University of Nebraska - Lincoln

DigitalCommons@University of Nebraska - Lincoln

1966

\title{
Behavior of the Australian Musk Duck and Blue-Billed Duck
}

Paul A. Johnsgard

University of Nebraska-Lincoln, pajohnsgard@gmail.com

Follow this and additional works at: https://digitalcommons.unl.edu/biosciornithology

Part of the Ornithology Commons

Johnsgard, Paul A., "Behavior of the Australian Musk Duck and Blue-Billed Duck" (1966). Papers in Ornithology. 61.

https://digitalcommons.unl.edu/biosciornithology/61

This Article is brought to you for free and open access by the Papers in the Biological Sciences at DigitalCommons@University of Nebraska - Lincoln. It has been accepted for inclusion in Papers in Ornithology by an authorized administrator of DigitalCommons@University of Nebraska - Lincoln. 


\section{BEHAVIOR OF THE AUSTRALIAN MUSK DUCK AND BLUE-BILLED DUCK}

\section{Paul A. Johnsgard ${ }^{1}$}

THE stiff-tailed ducks include a group of nine species currently placed in four genera (Delacour, 1959), of which only two (Oxyura and Biziura) possess the elongated and stiffened rectrices for which the group is named. Biziura is monotypic and consists of the Australian Musk Duck ( $B$. lobata), but Oxyura includes six species which are widely distributed on all continents and is represented in Australia by the Blue-billed Duck (O. australis). Intrageneric relationships and species limits in Oxyura are still somewhat uncertain ( $c f$. Delacour and Mayr, 1945, with Delacour, 1959), due to considerable external uniformity among most species and limited comparative information. Because of these taxonomic uncertainties and the fact that the stiff-tailed ducks tend to have highly varied and elaborate displays, a comparative study of their behavior patterns has been undertaken in hopes of better interpreting relationships in the group. As a first step in that study, the two Australian representatives were investigated in July and August of 1964, and the present paper summarizes my behavioral observations on these species. Some additional observations on the general behavior, vocalizations, and abundance of these and other species are published elsewhere (Johnsgard, 1965).

\section{Musk Duck}

Although similar to the typical stiff-tails in its body form and general behavior, the Musk Duck diverges from Oxyura in two important, respects. First, although the sexes are identical in coloration (unlike the situation in Oxyura), there is a remarkable sexual dimorphism in size, with adult males weighing from two to three times as much as females, and up to eight pounds or more. Second, the adult male Musk Duck is unique among waterfowl in its possession of a leathery lobe that hangs loosely from the lower mandible. Although the female possesses a small lobe it cannot normally be seen in the field, whereas that of the adult male reaches a size equal to or greater than the head itself. Except during display the lobe dangles quite loosely and flaps freely about in the wind or with head movements.

In spite of the relative abundance of the Musk Duck over much of southern Australia, surprisingly little has been published regarding its behavior. This is all the more remarkable considering the bizarre and

\footnotetext{
${ }^{1}$ Studies from the Department of Zoology and Physiology of the University of Nebraska (no. 368).
} 
conspicuous nature of its displays. V. N. Serventy (1946) and D. L. Serventy and Whittell (1951) provide the only detailed descriptions of displays, but my own observations do not closely agree with their accounts.

Prior experience with displays of other waterfowl, even with the typical stiff-tails, does not prepare one for a ready understanding of the Musk Duck's behavior. It is unlikely that the term "pair-forming displays" is appropriate for this species, for I saw nothing to suggest that pair bonds are present in Musk Ducks. Rather, I think that males conduct promiscuous relationships with any females they manage to attract, and thus natural selection has favored the evolution of elaborate displays having considerable "attraction value," as well as promoting sexual dimorphism in body size and strength. Indeed, the form of display in Musk Ducks is reminiscent of such species as the Capercaillie (Tetrao urogallus) which exhibit extreme sexual dimorphism and conspicuous displays that may attract females from some distance (Lumsden, 1961: 262-267). Whether males have a localized display area which they defend against the presence of other males is also open to question and could be resolved only with marked birds, but the only male-to-male aggression I observed occurred when other males closely approached a displaying bird; at other times males and females intermingled freely.

Display in male Musk Ducks was observed frequently by me while I was in northern Victoria from mid-July through early August, although the nesting season there does not begin until September or later. However, I observed no female displays of any kind, and suspect that the female's role is essentially a passive one of observing and presumably visually stimulating the male by her presence alone. The male displays which I observed are all similar and appear to represent a hierarchy of forms, of which at least three levels of ritualization, complexity, and timeinterval constancy can be recognized. I have called these the "Paddling Kick," the "Plonk Kick," and the "Whistle Kick."

Paddling Kick.- In all the display sequences which I observed from the outset, the Paddling Kick was invariably used as the beginning. As the bird moved forward in the water he lowered his head and neck toward the surface, the body and tail were held in a straight axis, and, with a strong kick, water was splashed to the rear and upward a distance of up to six or eight feet (Figure 1a). Often the two feet were not kicked in exact synchrony, but rather a double (or even triple) splash was sometimes produced, as might have been expected if the normal alternate paddling movement of the feet were not modified. The feet were lifted very high in the kick and sometimes could be seen as they were raised above the back. Although a loud and conspicuous splashing noise was produced, no vocalizations were heard. The bird's lobes appear at least 

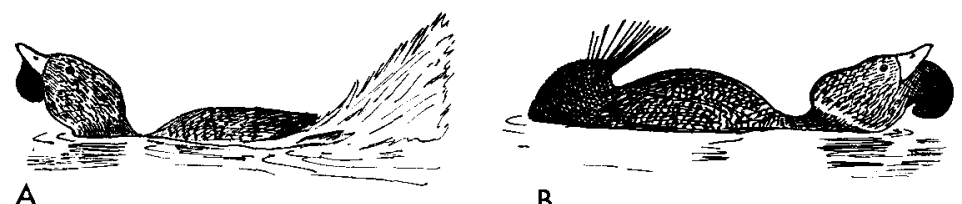

B
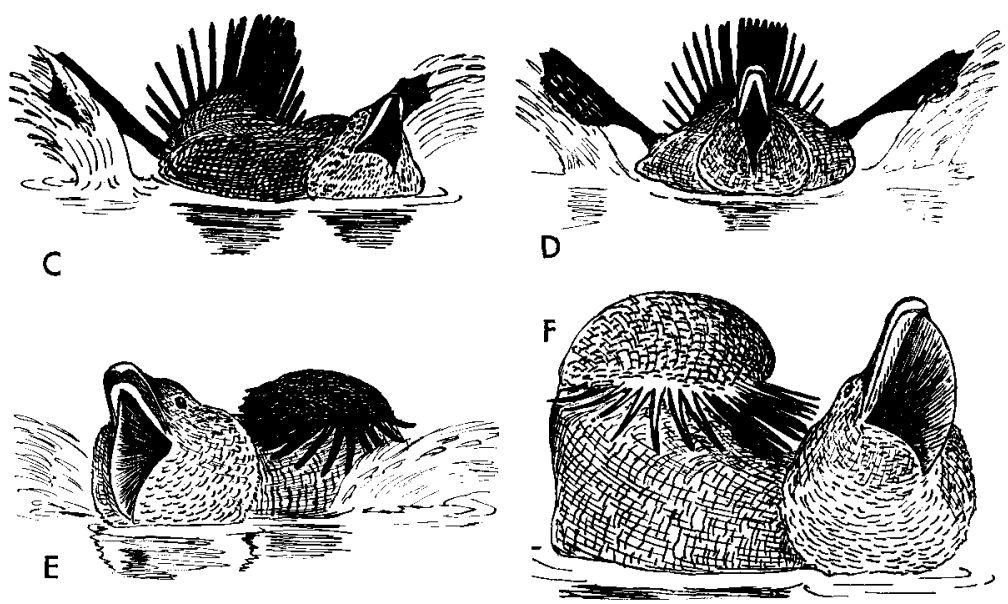

Figure 1. Musk Duck displays. A, Paddling Kick; B, Tail-cocking and lobe enlargement prior to Plonk Kick; C and D, Plonk Kick, two views; E, Whistle Kick; F, extreme degree of tail-cocking and subgular pouch inflation. (Drawn from frames of $16 \mathrm{~mm}$ motion picture.)

partially turgid during this display, and the tail is occasionally raised and lowered between displays. In spite of the force of the kick, not much forward movement results, since much of the power of the kick is directed upward; thus the bird's body is pushed down rather than forward. The number of Paddling Kicks given in a series was quite variable, the maximum I observed being 30. Normally, however, there are far fewer-as few as three or four may be performed before the male stops or begins to perform "Plonk Kicks." Of four complete sequences leading to Plonk Kicks, which I observed, the average number of Paddling Kicks was 13, and from frame analysis of motion picture sequences it was possible to determine time intervals between the beginnings of successive kicks. In 19 such intervals, the average time was 4.1 seconds (range, 2.4-8.3; standard deviation, 1.7). A possible variation of the Paddling Kick is a "Splash-dive," earlier reported by Serventy (1946) and Vic Lowe (pers. comm.) and observed once by me. The male dives quickly amid a great splash of water thrown up as the bird disappears from view. In all the cases where it has been observed, other males have been in view, and the display appears to have a hostile or threat function. 
Plonk Kick.-The Plonk Kick is perhaps the most commonly observed of the Musk Duck's displays. After a few Paddling Kicks the male typically begins an extended series of Plonk Kicks, in which the head is tilted upward and held rather stationary; the tail may be lowered, fanned and held cocked over the back (Figure 1b), or alternately moved between these two positions. The pendent lobe is thickened basally (it cannot be inflated) and assumes a typical semilunar shape, while the cheeks and throat are markedly expanded posteriorly, doubtless the result of inflation of a subgular pouch that occurs below and behind the tongue (Forbes, 1882). The resulting effect is a grotesque, almost reptilian, appearance (Figure 1c). In this posture the bird suddenly kicks simultaneously with both feet, sending splashes upward and laterally. The feet are not kicked directly back, as in the Paddling Kick, but rather are directed to the side and posteriorly, and thus the splash produced is not nearly as great as in the Paddling Kick. As the feet are brought back (Figure 1d) they strike the water surface sharply, and a surprisingly loud "plonk" or "kerplonk" sound is produced. I have no doubt that this noise is produced by the feet alone rather than vocally, as has been generally asserted. The feet emerge from the water near the bend of the wing, bringing with them a spray of water, pass laterally backward, and strike the water with opened webs near the tail. These Plonk Kicks are repeated with considerably more regularity than the Paddling Kicks, for an indefinite period. In timeanalyzed movie sequences, the average interval between 14 such displays was 3.3 seconds (range, 2.6-4.2; s.d., 0.43). In series timed by wrist watch in the field, 120 displays averaged 3.3 seconds apart (Table 1). I have counted as many as 51 Plonk Kicks in an unbroken sequence, and they commonly average 30 to 40 . In the event that no females are attracted by this time the male may revert to Paddling Kicks or even stop displaying altogether, but generally one or more birds will have approached by then to within a few feet of the displaying bird. The presence of such birds (females or other males) usually results in the male's beginning to perform Whistle Kicks, although these may also be initiated in the absence of other individuals.

Whistle Kicks.-These kicks are a more extreme manifestation of the posturing assumed during the Plonk Kick. The spread tail is usually kept fully cocked and closely pressed against the back. The head is held low over the water, tilted upward so that the fully turgid lobe almost touches the surface, and the neck is usually almost submerged. In this posture the bird suddenly flicks his feet simultaneously outward and backward, causing jets of water to be thrown out on both sides of the body for a foot or two (Figure 1e). Occasionally only a single jet is produced, especially when a female is closely parallel to the male, in 
TABLE 1

Time Constancy of Musk Duck Displays

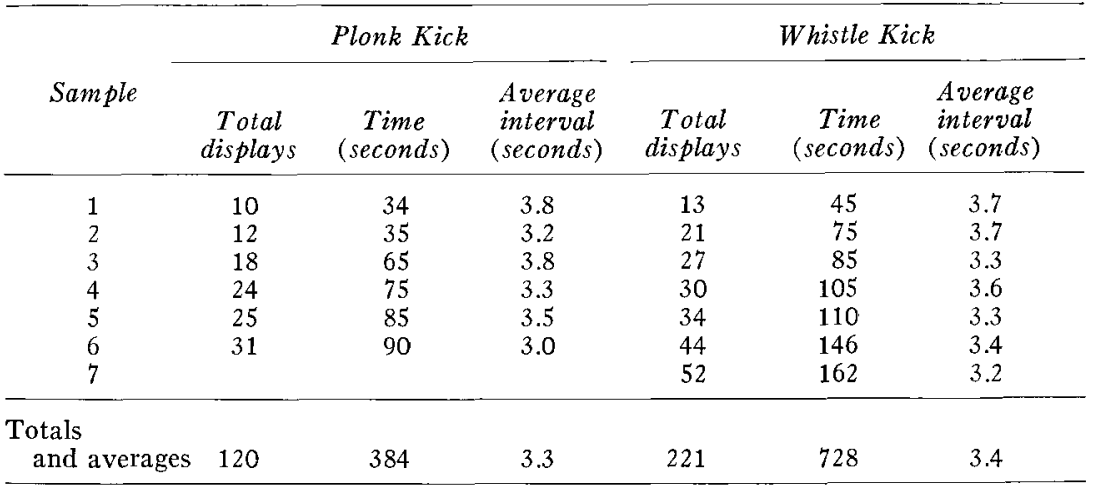

which case the splashing water may strike the nearby bird. Serventy (1946) attributed these large splashes to wing movements on the grounds that the feet are placed too far posteriorly, but motion picture sequences clearly show that the feet alone are responsible and that they can be brought very far forward along the side of the body. At times there does appear to be a simultaneous jerk of the folded wings, but they remain closely appressed to the body and could not be responsible for the splashes produced.

In extreme posturing, such as occurs when other birds are nearby, the male raises his head and fully cocked tail from the water between splashes, so that the body appears almost U-shaped and the under tail coverts are visible from in front of the bird (Figure 1f). This posture is especially frequent when other males approach. Surprisingly, such males will often swim up to within a foot or so of displaying birds, watching them intently. Females are also strongly attracted to such displaying males, but usually remain a few feet away from them. Depending on the location of such "onlooker" birds, the displaying male will often back-paddle or move laterally between splashes, obviously attempting to establish a particular position relative to other birds.

With each splash a sharp, clear whistled note is uttered, which the uninformed observer would probably fail to attribute to such a large bird. Indeed, the note is surprisingly similar to the call of the Narrow-billed Cuckoo (Chalcites basalis), which occurs in the same area, except that the call stops abruptly rather than dropping in volume and frequency. At close range a much softer preceding note can be detected, which is similar to the sound produced by blowing over the mouth of an empty bottle. The timing of these whistles and splashes is remarkably constant; of a 
total of 44 intervals analyzed from film, the intervals varied from 2.7 to 4.3 seconds, and averaged 3.7 seconds. The standard deviation of this sample (based on several birds) was 0.28 seconds, but individual birds appeared to show even greater time uniformity. Thus, one male exhibited minimum and maximum intervals of 3.75 and 4.00 seconds in 10 displays. For 221 displays timed in the field, there was an average interval of 3.4 seconds between displays (Table 1).

In the event that a male's Whistle Kicks fail to attract any females, he will often revert for a time to Plonk Kicks, then resume Whistle Kicks. In one sequence of 78 displays I counted there were 13 shifts between Whistle Kicks and Plonk Kicks before the male finally stopped displaying altogether. However, should any females be attracted, the Whistle Kicks are likely to proceed in a long, unbroken series. The longest single series of displays I counted was 11 Paddling Kicks followed by 51 Plonk Kicks and finally 64 Whistle Kicks. This series was terminated when another male approached one of the "onlooker" females, and the displaying male suddenly came out of his posturing and dived toward the intruding male. This action caused an immediate frantic scattering of all the Musk Ducks in the vicinity. Although $\mathbf{I}$ observed several such attempted male-to-male attacks, only one I saw ever resulted in an actual fight. This was a vicious, wing-beating, biting battle between two large males, one of which finally escaped and retreated as rapidly and inconspicuously as possible to shore, where it lay stretched out immobile on the bare beach for several minutes. Thinking that it might be badly hurt, I approached, whereupon the bird crawled back to the water and stealthily swam away.

Copulation.-I did not personally observe copulation, and it has not been described in the literature, but I have obtained two accounts of personal observations by Vic Lowe and Angus Robertson. Mr. Lowe's account is quite complete and I will quote his original notes:

A Musk Duck had been displaying for some minutes, under observation, with lobe inflated, neck feathers puffed up and the usual splashing with feet. Three females gradually swam near and the male selected one for attention and spent some two minutes sidling near, turning, retreating a few feet and returning, ranging alongside and all the time kicking side splashes, more than usually at right angles to the body and only about half-strength, often from $1 \frac{1 / 2}{2}$ feet sprinkling the female's head. She appeared quite indifferent and calmly rode on the water exactly as did the other females some ten feet away, which birds viewed the situation calmly too.

Finally sidling close to the female, the male in a flash enveloped her with a swift movement of a wing, pressed her beneath him, trod her submerged for about $1 / 4$ minute and finally copulated. Immediately the male twisted a quarter circle and with head submerged and body streamlined above the water "steamed" at speed for 12 feet behind the female, lifted his head, and calmly turned at rest. (I had not before seen this submarine-like act, as when drake 
chases drake, his head is not submerged.) As the male released the female she surfaced, reared upright and flapped her wings to settle her plumage-in the common manner of ducks-and cruised listlessly and normally away.

Robertson noted that two females were observing a male perform the same sort of high-intensity posturing (doubtless Whistle Kicks) described above, when suddenly one chased the other away, returned to the male, and was immediately mounted. Following treading, during which the female was submerged, the birds separated and the female floated to the surface while the male, with head submerged, swam rapidly around in a small circle, at no time more than two feet from the female. The male then mounted the female a second time and an apparently successful copulation followed.

Both of these observations strongly suggest that there is no special mutual precopulatory behavior, but rather that the male copulates with any females that he manages to attract through his general display activities. This absence of mutual precopulatory displays further supports the probability that a promiscuous mating system exists in the Musk Duck and places a strong selective premium on mechanisms effective for attracting females.

\section{Blue-BILled Duck}

The Blue-billed Duck has a range in Australia similar to that of the Musk Duck, but it is a considerably rarer bird, inhabiting the reedy and permanent water areas of the inland, and only rarely occurring in large numbers anywhere. However, I found it to be remarkably common on Kangaroo Lake, near Kerang, Victoria, where several thousand birds were present during July and early August. Vic Lowe (pers. comm.) informed me that this represented an unusually large and primarily transient winter population. Of these birds, most were males, and by early August a minority of these had assumed the ruddy coloration and brilliant blue bill of the breeding condition. As with the Musk Duck, the nesting season does not begin in the Kerang area until September or later, but pairforming displays were observed from 22 July until I left the area on 7 August.

Various displays of the Blue-billed Duck have been described previously; the accounts by Wheeler (1953), Brown (1949), and Scott (1958) are perhaps the most significant. These authors described various displays, most of which I was able to interpret within the framework of my own observations. A summary of the male displays which I observed follows, with reference to previous descriptions of these same displays.

Dab-preening.-This is the name given by Brown (1949) to one of the most common of male displays, and the one which most commonly initiates 
a display sequence. From a normal swimming posture the male suddenly jerks his head up and down several times, simultaneously pressing his bill against the breast. The display is clearly a ritualized form of breast preening, but is much more rapid than normal preening, and the male tends to face the female. Although these Dab-preens are usually given in short series of from 3 to 6 , I counted one series of 20 . They appear to be silently performed (Figure 2d).

Head-pumping.-A silent, vertical, and rather rapid pumping of the horizontally held head occurs in two quite different situations. It occurs frequently in both sexes apparently as a diving intention movement, when the birds have been frightened and are swimming in an alert, tail-cocked posture. In males the same movement, or at least a very similar one, occurs as an immediate preliminary to the major male display of "Sousing." In this situation the pumping begins with the tail flat on the water, but as the pumping progresses, the tail is gradually cocked up beyond the vertical, and upon reaching that position the Sousing display almost invariably begins. I have observed from as few as 1 to as many as 11 Head-pumping movements prior to Sousing, but the average of eight sequences was 4.2 .

Sousing.-This display has been variously described by Wheeler, Brown, and Scott, but these authors gave it no definite name and I am using one suggested to me by Mr. Vic Lowe. Sousing, the most elaborate and remarkable of the Blue-bill's posturings that I observed, begins in a neckstretched, tail-cocked posture, with the male usually facing the female (Figure 2a). The bird then suddenly throws his head forward and downward (Figure 2b), his neck inflated enormously; as the bill and throat strike the water the bird convulsively jerks his head back toward his breast, and at the same time paddles with the feet to maintain a somewhat arched position of the body at the water surface (Figure 2c). For several seconds the male continues a series of these jerky head movements, thus repeatedly splashing the water with its throat and bill. In 13 such displays I analyzed, there were from 3 to 7 jerks (average 5.1). The male then lowers his tail (which has remained cocked up to this point) below the water and simultaneously lowers his head so that only the arched back is visible. In this posture, which may be held a variable length of time, the male remains stationary or may swim backward for a foot or so. Finally, the head is raised and shaken and the display is usually terminated by a variable number (up to 5; average for 15 is 2.5) of bill-dipping and head-shaking movements. Although Brown and Scott both mention partial wing extension or flopping movements, I have never observed this. 

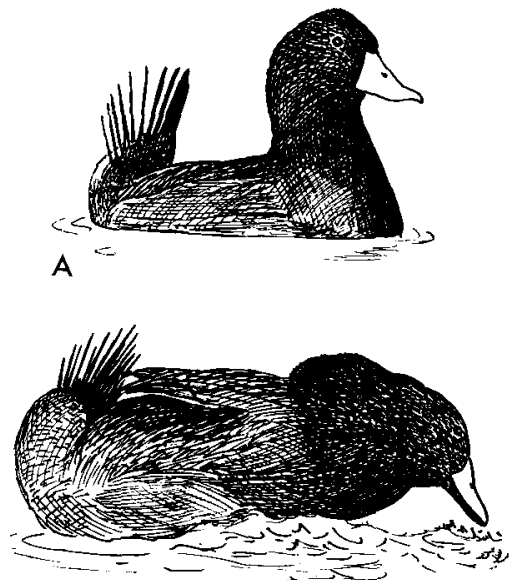

C

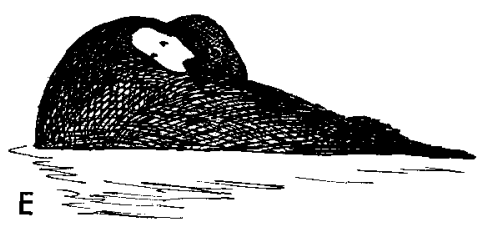

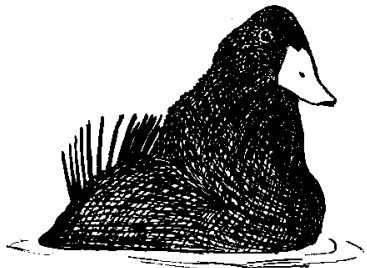

B

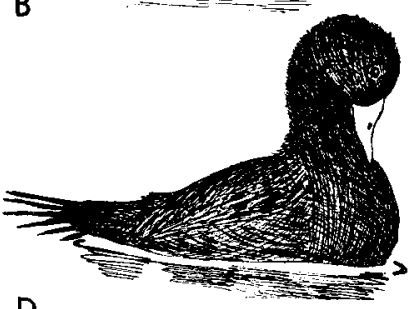

D

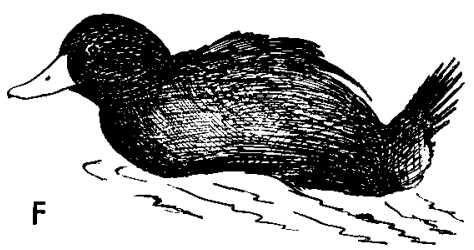

Figure 2. Blue-billed Duck displays. A, Tail-cocking prior to Sousing; B, beginning of Sousing; C, Neck-jerking phase of Sousing; D, Dab-preening; E, Head-rolling; F, Lurching. (Drawn from frames of $16 \mathrm{~mm}$ motion picture.)

Two features of the display are of particular interest: its origin and the mechanism of neck inflation. My first impression of the display was to think that it might represent ritualized bathing movements, but close examination of film sequences indicate that the body movements are very different from those of a bathing duck, and instead the jerky head movements seem to have the function of expelling air from the neck. Nonetheless, I have heard no sounds produced in the display other than the fairly conspicuous splashing noises. I have examined the tracheal and esophageal anatomy of a male in breeding condition, and found no tracheal air sac of the type occurring in the North American Ruddy Duck (Oxyura jamaicensis). However, the esophagus appears capable of considerable distention, and thus I am certain that the neck is inflated through the swallowing of air, probably in the same manner as in the Argentine Ruddy Duck, Oxyura vittata (Wetmore, 1926: 85-86). Therefore, I have concluded that the Sousing display evolved as a means of alternately inflating and deflating the esophagus. Furthermore, although tail-cocking and jerky head movements are also common to the North American Ruddy Duck's "Bubbling" display (Helen Hays, unpublished 
MS), I feel convinced that the two displays are of independent origin and are similar only through convergence. I did not observe Sousing in females, but Vic Lowe has recorded it. I did observe apparent neck inflation in females.

Head-rolling ("Cheeking" of H. Hays, MS).-This display, which differs from normal head-rolling only in its context and in the fact that a quite regular alteration of left and right rolling movements occurs, was fairly frequently observed. Usually between three and six such movements are made, with the cheeks being rubbed rapidly over the scapulars of the right or left side (Figure 2e). Head-rolling is usually terminated by the "Wing-flapping" or "Lurching" displays.

Wing-flapping.-This is a distinctly ritualized and conspicuous display, occurring independently or after various other displays such as Headrolling or the "Display Flight." As an independent display it is usually preceded by a tail shake and single head-dipping movement, but when it is used in conjunction with other displays the tail shake appears to be absent. The wings are quickly flapped a few times (three in each of two filmed sequences), and the whirring sound produced may be of behavioral significance.

Lurching.-I have observed this display only as a finale to other display sequences such as Wing-flapping and Head-rolling. In these instances the bird would become momentarily rigid, back-paddle a few inches, then suddenly lurch forward in the water as if it had been attacked from below (Figure 2f). Usually there is rather little forward movement of the body, but a conspicuous gurgling and splashing sound of water is produced.

Motor-boating.-I observed this display on only four occasions, and am uncertain of its significance. It greatly resembles the "Hunched-rush" (H. Hays, MS) return of male North American Ruddy Ducks to females after chasing other males, but when $\mathrm{I}$ observed it in the Blue-billed Duck it appeared to be a distinct and independent display. The male would suddenly begin "planing" over the water with his head erect, breast high, tail flattened, and by his rapid paddling produce a conspicuous trailing in the water, similar to that made by a speeding motorboat. As in the Sousing and Lurching displays, the splashing sounds of water probably enhance the visual aspects of display. In two of the four observations the males swam toward females; in the others there was no apparent orientation.

Display Flight ("Ring Rush" of H. Hays, MS).-This display was observed only twice in the Blue-billed Duck, and it appeared to correspond exactly to the comparable display of the North American Ruddy Duck. It consists of a short, "buzzing" flight by the male slightly over the water 
surface. In one of the two cases the male terminated the flight by billdipping and Wing-flapping.

Aggressive Chase.-On a few occasions males were observed to chase other males in the characteristic manner of male Ruddy Ducks, with the neck and back feathers ruffled and head held close against the breast.

Preening-dorsally.-This posture was observed a few times as a part of various display sequences, and is possibly ritualized. On one occasion it occurred between Wing-flapping and the Lurching display, while on another it appeared to be a preliminary to Head-pumping and subsequent Sousing.

Gaping.-Both sexes frequently gape aggressively. At close range a soft and rather rapid Tet-tet-tet . . note can be heard, which is uttered by females and possibly also by males.

Diving. - I did not observe any diving that I interpreted as a part of display, but Brown (1949) reported short dives by a displaying male, Wheeler (1953) observed shallow dives interspersed with Dab-preening and Head-pumping, and Vic Lowe (pers. comm.) has observed both males and females diving under one another in an apparent display.

Behavior of females.-As indicated above, I have observed Gaping, Head-pumping and tail-cocking in females, the two last occurring together when the female is frightened and about to dive. I did not observe anything that could be interpreted as inciting or as a specific stimulus to elicit male displays; rather, the females Gaped at or actually attacked males that approached them. The only female vocalizations I heard were those in Gaping.

Copulation.-I observed neither copulations nor any obvious precopulatory behavior. Wheeler (1953) has reported the only description of copulation known to me, based on a single observation. In that instance the male chased the female at high speed, at times under water, finally catching her. During copulation the female was completely submerged, and following treading both sexes preened extensively. It is probable that this does not represent normal copulatory behavior.

\section{Discussion}

The Musk and Blue-billed ducks differ basically in that the latter appears to have definite, probably monogamous, pair bonds, while in the former a presumably promiscuous mating situation exists. However, both species possess mechanisms for inflating the neck or head, a characteristic apparently typical of all the stiff-tails except Thalassornis. In addition, both species exhibit displays that produce noises through kicking or vigorous water movement. I have suggested (1960: 41) that these 
can be related to the ecology of stiff-tails, which inhabit overgrown marshes where auditory signals might prove more effective than visual ones. In both species, however, the inflation mechanism appears to contribute little or nothing to sound production during display, which is not true of the North American Ruddy Duck. At least in the Musk Duck the male's lobe and enlarged throat appear simply to reinforce visually the impressive combination of splashing and vocalizations during display.

A second noteworthy feature of the behavior of the two species is the fact that, although one has no congeneric relatives and the other lacks contact with any, the male displays are surprisingly elaborate. This absence of sympatric congeners greatly reduces the probability that the displays function as isolating mechanisms, since the possibility that Musk Ducks might hybridize with the much smaller Blue-billed Ducks seems remote. Therefore, sexual selection would appear to provide the only explanation for the elaborate male displays, and this possibility seems particularly applicable to the Musk Duck, in which the reproductive potential of a single successful male is probably considerable.

It is much too early to evaluate critically the taxonomic significance of these present observations, but a few general points can be made. For example, neither the details of displays nor the mechanisms of neck inflation in the Blue-billed Duck correspond to those of the North American Ruddy Duck. The only other species of stiff-tail known to have a similar esophageal neck-inflation mechanism is the Argentine Ruddy Duck, but too little is presently known of that species' behavior patterns to judge its possible relationships to the Blue-billed Duck. There is little reason to doubt that the Musk Duck's nearest relatives are the species of Oxyura. In fact, most of the differences in size and male characteristics that distinguish the genus Biziura can be explained by the intensive sexual selection that must have influenced the direction of evolution in the Musk Duck.

\section{Summary}

Sexual displays of the Musk Duck and Blue-billed Duck are described and illustrated. The displays of male Musk Ducks comprise a series of three forms exhibiting increasing ritualization, complexity, and timeinterval constancy. All of them have conspicuous auditory characteristics as well as variously conspicuous visual features. Displays in the species appear to have evolved under the influence of intense sexual selection resulting from what is probably a more completely promiscuous mating system than occurs in any other species of Anatidae. These selective pressures have also probably promoted the evolution of such features 
as large size and extreme sexual dimorphism that distinguish the genus Biziura from the typical stiff-tails (Oxyura). Displays in the Blue-billed Duck likewise embody a combination of auditory and visual characteristics, and include a large number of variably ritualized postures, several of which are clearly derived from comfort movements or intention movements. Certain similarities between the major displays of the Blue-billed Duck and the North American Ruddy Duck are thought to be the result of convergence, and a close relationship between these species is not indicated.

\section{ACKNOWLEDGMENTS}

This study was done under a grant (No. GB 1030) from the National Science Foundation. Although a number of Australians went to great efforts on my behalf, I am especially indebted to Vic and Tom Lowe and their families, whose assistance in every possible respect did much to make my efforts both rewarding and immensely enjoyable. Mr. Roy Wheeler likewise assisted greatly with my early planning and establishment of helpful contacts. The Victoria Fisheries and Wildlife Department were extremely helpful and contributed greatly toward expediting my plans, and Drs. D. Dorward and A. J. Marshall of Monash University likewise facilitated my efforts considerably.

\section{Literature Cited}

Brown, A. G. 1949. Display of Blue-billed Ducks. Emu, 48: 315.

Detacour, J. 1959. The waterfowl of the world. Vol. 3. London, Country Life Ltd.

Delacour, J., and E. Mayr. 1945. The family Anatidae. Wilson Bull., 57: 3-55.

Forbes, W. A. 1882. Note on some points in the anatomy of an Australian duck (Biziura lobata). Proc. Zool. Soc. London, 1882: 455-458.

JohnsGard, P. A. 1960. Comparative behaviour of the Anatidae and its evolutionary implications. The Wildfowl Trust, 11th Annual Report, pp. 31-45.

Johnsgard, P. A. 1965. Observations on some aberrant Australian Anatidae. The Wildfowl Trust, 16th Annual Report, pp. 73-83.

Lumsden, H. G. 1961. The display of the Capercaillie. Brit. Birds, 54: 257-272.

Scotr, P. 1958. Notes on Anatidae seen on world tour. The Wildfowl Trust, 9th Annual Report, pp. 69-72.

Serventy, V. N. 1946. Display in the Musk Duck. Emu, 45: 318-321.

Serventy, D. L., AND H. M. Whittell. 1951. Handbook of the birds of western Australia. Perth, Paterson Brokensha Pty. Ltd.

Wetmore, A. 1926. Observations on the birds of Argentina, Paraguay, Uruguay and Chile. U. S. Natl. Mus., Bull. 133: 1-488.

Wheeler, J. R. 1953. Notes on the Blue-billed Ducks of Lake Wendouree, Ballarat. Emu, 53: 280-282.

Department of Zoology and Physiology, University of Nebraska, Lincoln, Nebraska. 